\title{
Clinical, haemodynamic, and coronary angiographic correlates of angina pectoris in patients with severe aortic valve disease ${ }^{1}$
}

\author{
Lotfy L. Basta, Dean Raines, Sakib Najjar, and J. Michael Kioschos \\ From the Cardiovascular Division, Department of Internal Medicine, University of Iowa, and VA Hospitals, \\ Iowa City, Iowa 52242, U.S.A.
}

Of 88 consecutive patients aged 20 to 77 years with severe symptomatic aortic valve disease requiring surgery, 5I patients had angina pectoris; of these 5I, $4 I$ had predominant aortic stenosis and Io had severe aortic regurgitation. All patients with angina pectoris underwent coronary angiography; significant coronary arterial disease was encountered in 24 per cent of those with aortic stenosis and 20 per cent of those with aortic regurgitation. By contrast, of 37 patients without angina pectoris 19 underwent coronary arteriography; none showed significant coronary artery disease $(P<0.05)$.

Among patients with angina pectoris, 17 per cent of those with aortic stenosis experienced prolonged, rest or nocturnal pain, compared to 70 per cent of those with aortic regurgitation $(P<0.005)$. At the time of onset of angina pectoris, there were features of heart failure in 34 per cent of those with aortic stenosis, and in 90 per cent of those with aortic regurgitation $(P<0.005)$. Nitroglycerin promptly relieved angina pectoris in 56 per cent of patients with aortic stenosis and in 50 per cent of those with aortic regurgitation $(P>0.05)$. Neither the pattern of angina pectoris nor the response to nitroglycerin was dependent upon the coexistence of significant coronary artery disease.

In patients with aortic stenosis, there was no significant difference between those with angina pectoris and those without angina with regard to left ventricular end-diastolic volume, end-diastolic pressure, ejection fraction, peak systolic pressure, wall thickness, cardiac index, or the product of these factors. In patients with aortic regurgitation, cardiac index was significantly lower $(P<0.05)$, left ventricular end-diastolic volume tended to be larger, and ejection fraction tended to be lower in patients with angina pectoris as opposed to those without angina pectoris.

Angina pectoris is a common symptom of severe aortic valve disease and is probably caused by a myocardial oxygen demand that exceeds supply. Earlier observers reasoned that angina pectoris should be particularly common in patients with aortic regurgitation because of low arterial diastolic pressure and, presumably, decreased coronary perfusion (Contratto and Levine, 1937). It was realized subsequently that angina pectoris is more commonly seen in aortic stenosis and that it is independent of the coexistence of aortic regurgitation (Contratto and Levine, 1937; Friedberg and Sohval, 1939) or coronary atherosclerosis (Mackenzie, 1925; Boas, 1922; Tuohy and Eckman, 1931; Received 17 May 1974.

${ }^{1}$ Supported by a College of Medicine grant and by a Program Project grant.
McGinn and White, 1934; Kumpe and Bean, 1948).

Recent studies on myocardial energetics have shown that myocardial oxygen consumption per beat is determined primarily by ventricular pressure, intraventricular volume, and myocardial mass, as well as by the contractile state of the heart (Sonnenblick and Skelton, I97I). Generally, the oxygen cost is far greater with 'pressure work' as opposed to 'volume work' (Braunwald, 1971). Furthermore, it has been shown from animal experiments that volume-induced hypertrophy is accompanied by normal myocardial oxygen consumption per unit muscle mass, whereas pressure-induced hypertrophy is associated with abnormal myocardial energetics (Cooper et al., 1973). Moreover, when hypertrophy is complicated by heart failure, the 
myocardium utilizes oxygen less efficiently for tension development by comparison with nonfailing myocardium (Gunning and Coleman, 1973). The implications of these and other findings in the genesis of angina pectoris in severe aortic stenosis as opposed to severe aortic incompetence need to be examined. In addition, the contribution of significant coronary atherosclerosis to ischaemic cardiac pain in adults and middle-aged patients with aortic valve disease warrants further study.

We studied our adult patients with severe aortic valve disease requiring surgery with the objectives of, I) definining the incidence of angina pectoris and its clinical pattern in patients with severe aortic regurgitation in comparison to those with predominant aortic stenosis; 2) identifying the frequency of significant coronary disease in patients complaining of ischaemic chest pain and in those who did not have chest pain but underwent coronary arteriography; 3) studying left ventricular haemodynamics, volumes, and wall thickness for possible features that characterize patients with angina pectoris and cast light on the pathogenesis of chest pain in these patients.

\section{Patients and methods}

The study comprises 88 consecutive patients with symptomatic severe aortic valve disease requiring aortic valve replacement at the University of Iowa and Veterans Administration Hospitals between 1968 and 1973 . There were 68 men and 20 women, with an age range of 20 to 77 years. A detailed history was obtained in each case by at least three independent observers. A diagnosis of angina pectoris was made when the patient complained of episodic diffuse chest pain that was consistently interpreted to signify ischaemia. Patients' workup included complete physical examination, $x$-rays, electrocardiogram, phonocardiogram, cardiac impulse, and carotid pulse recordings, as well as cardiac catheterization. Rightsided catheterization was obtained by a Swan or Gensini catheter using standard technique. Left-sided catheterization was obtained retrogradely from the brachial artery, or by the transseptal technique of Brockenbrough and Braunwald (1960). Aortic pressure was obtained by NIH catheter No. 7-8 introduced retrogradely from the right femoral artery. Simultaneous left ventricular and aortic pressures, and left ventricular and pulmonary artery wedge or left atrial pressures were obtained by equisensitive Statham strain gauge transducers (model p23 Db), with reference to the midchest level, and were recorded on an Electronics for Medicine $\left(D_{16} E F M\right)$ photographic recorder. Left ventricular cineangiograms were filmed in $30^{\circ}$ right anterior oblique position. Renografin-76, $0.75-\mathrm{I} \mathrm{ml} / \mathrm{kg}$ body weight, was injected into the left ventricle via a No. 7-8 angiocatheter or transseptal catheter at a rate of 15 $\mathrm{ml} / \mathrm{s}$ using a cordis-I I injector. An aortic root injection was performed in the left anterior oblique position.
Cineangiograms were taken at 32 frames/s. Ventricular volumes were redrawn from angiograms and corrections were made for magnification through the use of I cm grid filmed at the mid-chest level, according to the method of Greene et al. (1967). Only technically acceptable beats were used for volume measurements. Ventricular volumes were calculated by assuming that the ventricle was ellipsoidal (Dodge, Hay, and Sandler, I962) and were corrected (c) by the regression equations: $\mathrm{EDV}_{\mathrm{c}}=\mathrm{EDV} \times 0.92-32.5 ; \quad \mathrm{ESV}_{\mathrm{o}}=\mathrm{ESV} \times 1.02-4.4$ and $\mathrm{SV}_{\mathrm{c}}=\mathrm{SV} \times 0.79-\mathrm{I} 4.8$ (Kennedy, Trenholme, and Kasser, 1970), where EDV is end-diastolic volume, ESV is endsystolic volume, and SV is stroke volume.

The ejection fraction was calculated as angiographic stroke volume/end-diastolic volume. Regurgitation volumes were calculated by the difference between the angiographic and Fick stroke volumes (Sandler et al., 1963).

Left ventricular wall thickness in the end-diastolic phase was measured at the midpoint of the anterior cardiac border in the right anterior oblique view.

Coronary arteriograms were obtained in the right anterior and left anterior oblique views using Sones, Judkins, and/or Amplatz catheters. A significant coronary artery lesion was taken to indicate at least 75 per cent occlusion of the lumen.

Severe aortic stenosis was considered the predominant lesion when the mean left ventricular-aortic gradient exceeded $50 \mathrm{mmHg}(6.66 \mathrm{kPa})$ in the absence of more than mild aortic regurgitation. Severe aortic regurgitation was considered the predominant lesion when the regurgitation fraction exceeded 50 per cent of the angiographic stroke volume, and the left ventricular-aortic peak systolic gradient was less than $30 \mathrm{mmHg}(4 \mathrm{kPa})$. Borderline cases and those associated with significant mitral valve disease were excluded.

\section{Clinical features of our cases}

Patients were divided into 4 groups.

I) Aortic stenosis with angina pectoris This group included 31 men and ro women, with an age range of 38 to 77 years (mean 57). Angina pectoris was exclusively related to exertion in 28 patients, recurred only at night and during rest in 3 cases, and recurred both with exertion and at rest in 9 patients. Fourteen patients $(34 \%)$ presented primarily because of shortness of breath in the form of paroxysmal nocturnal dyspnoea and/or effort dyspnoea, and 3 were in frank congestive cardiac failure. Fifteen patients (37\%) gave a history of syncope. Physical findings were consistent with severe aortic stenosis. Chest $x$-ray showed a cardiothoracic ratio of less than 0.5 in II patients, of 0.5 to 0.55 in 14 patients, of 0.55 to 0.6 in 13 patients, and in excess of 0.6 in 3 instances. The majority had aortic valve calcification. Four patients had severe pulmonary congestion. The electro- 
cardiogram was normal in I patient, showed left bundle-branch block in 4 , left ventricular hypertrophy without ST-T changes in 2, and left ventricular hypertrophy with 'strain' in 34 patients.

2) Aortic stenosis without angina pectoris This group included 19 men and 8 women, with an age range of 34 to 68 years (mean 54). All were symptomatic; I5 patients were in functional class II (N.Y.H.A. Classification), Io were in class III, and 2 were in frank congestive cardiac failure. Two patients complained of paroxysmal nocturnal dyspnoea as well as effort dyspnoea. A history of syncope was obtained in II (4I\%) and possibly in I other patient. Physical findings were consistent with severe aortic stenosis. Chest $x$-ray showed a cardiothoracic ratio of less than 0.5 in 4 patients, 0.5 to 0.55 in 8 patients, 0.55 to 0.6 in 9 patients, and more than 0.6 in 6 instances. The majority had aortic valve calcification. Severe pulmonary congestion was noted in 3 cases. The electrocardiogram was normal in I patient, showed right bundlebranch block in $I$, and revealed left ventricular hypertrophy in 24 patients, all but 2 of whom had 'strain' pattern.

3) Aortic regurgitation with angina pectoris This group included 9 men and I woman, with an age range of 32 to 62 years (mean 47). Angina pectoris was related only to exertion in 3 patients, was exclusively nocturnal and occurred at rest in 2 , and recurred at rest, during sleep as well as with exertion, in 5 patients. Shortness of breath was a prominent feature in 9 patients; it was precipitated by moderately severe exercise (class II) in 2, caused pronounced limitation of exercise tolerance (class III) in 6 patients, and I patient was in frank congestive cardiac failure (class IV). Eight patients experienced attacks of paroxysmal nocturnal dyspnoea. Syncope was a prominent feature in 2 cases. Signs of severe aortic regurgitation were obvious in all patients. Chest $x$-ray showed a cardiothoracic ratio of $0.5-0.55$ in 2 patients, $0.55-0.6$ in 2 others, and more than 0.6 in 6 cases. Severe pulmonary congestion was observed in 4 patients. The electrocardiogram revealed voltage criteria for left ventricular hypertrophy in all patients, and there was 'strain' pattern in 6 of them.

4) Aortic regurgitation without angina pectoris This group included 9 men and I woman with an age range of 20 to 57 years (mean 33). The main presenting symptom was shortness of breath which was precipitated by moderate exertion in 2 (class II) and mild exertion in 8 patients (class III). Six patients complained of paroxysmal nocturnal dyspnoea, and 3 experienced syncope or dizziness.
Physical findings suggested severe aortic regurgitation in each of them. The chest $x$-ray showed a cardiothoracic ratio of $0.5-0.55$ in 4 patients, $0.55-0.6$ in 3 patients, and more than 0.6 in 3 others. The electrocardiogram was within normal limits in $\mathrm{I}$ and showed left ventricular hypertrophy in 9 patients, 7 of whom had 'strain' pattern.

Incidence of significant coronary disease and its relation to angina pectoris (Fig. I)

All 5I patients with angina pectoris underwent coronary angiography. Of 37 patients without angina pectoris, I9 were similarly studied. Those who did not have coronary angiograms were studied before 1971 when this investigation became routine, in our laboratory, for all candidates for aortic valve replacement. Significant coronary artery disease was encountered in 24 per cent of those with angina pectoris as opposed to none of those without angina $(P<0.05)$.

Among patients with aortic stenosis and angina pectoris, there were 3 patients with significant $(>75 \%$ stenosis) 3-vessel coronary disease, 2 patients with 2-vessel disease, 4 patients with isolated complete right coronary artery occlusion, and I patient with isolated left anterior descending occlusion. Four other patients had either minimal or significant coronary lesions (occlusion of $50 \%$ or less).

Among patients with aortic regurgitation and angina pectoris, one had complete occlusion of the circumflex coronary artery, and another showed complete occlusion of the right coronary artery,

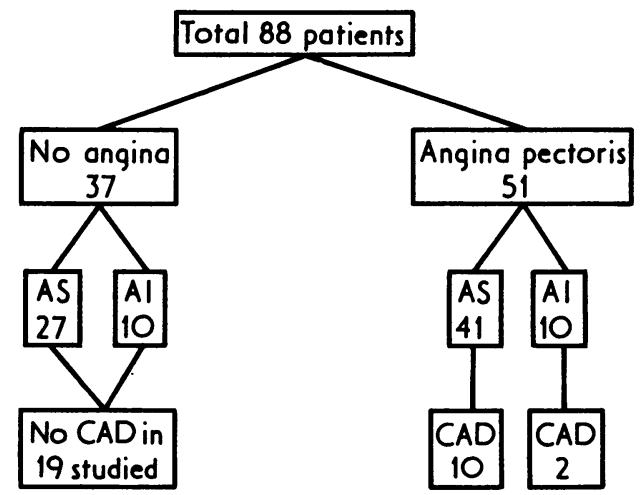

FIG. I The distribution of patients in the different groups and the incidence of significant coronary artery disease in the group with angina pectoris versus the group without angina. $A S=$ predominant aortic stenosis; $A I=$ severe aortic regurgitation; $C A D=$ significant coronary artery disease $(75 \%$ or more occlusion.) 
whereas the rest of the patients did not have demonstrable coronary lesions.

Among the I9 patients without angina pectoris who underwent coronary arteriography, insignificant coronary disease (less than $50 \%$ occlusion) was noted in 4 instances; it was limited to the left anterior descending vessel in 3 patients and was diffuse in $\mathbf{I}$.

Clinical characteristics of angina pectoris and its relation to coronary disease in aortic stenosis versus aortic regurgitation (Fig. 2)

Of patients with aortic stenosis and angina, 27 $(66 \%)$ presented primarily because of chest pain; and 7 of these had significant coronary disease. By contrast, only I patient with aortic regurgitation (10\% of those with angina) presented primarily because of the chest pain $(P<0.005)$; he had complete occlusion of the left circumflex coronary artery. Angina pectoris in conjunction with aortic stenosis was mainly related to exertion, whereas anginal pain occurred almost as frequently at night or while resting as it was related to effort, in patients with severe aortic regurgitation $(P<0.005)$.

At the time of development of angina pectoris, 34 per cent of patients with aortic stenosis had features of heart failure manifested by paroxysmal nocturnal dyspnoea, very limiting effort dyspnoea (N.Y.H.A. functional class III), or frank congestive heart failure; these features were present in 90 per cent of patients with aortic regurgitation $(P<0.005)$.
Nitroglyerin (Fig. 3) was used by 36 patients with aortic stenosis for relief of angina pectoris. Of these, I9 patients experienced prompt relief, while the remaining patients either did not benefit from nitroglycerin or were uncertain about its value, mainly because of the short duration of chest pain. Four patients with angina pectoris and aortic regurgitation reported prompt relief with nitroglycerin, while 4 others experienced no benefit from the drug or were not certain about its value. The beneficial effects of nitroglycerin were not dependent upon the coexistence of coronary artery disease (Fig. 3).

\section{Haemodynamic findings in relation to angina pectoris (Tables $I$ and 2 )}

By comparing patients with symptomatic stenosis without angina pectoris and those with angina pectoris, it was noted that there was no significant difference between the two groups with regard to left ventricular end-diastolic volume, left ventricular end-diastolic pressure, ejection fraction, cardiac index, peak systolic pressure, estimated left ventricular wall thickness or the product of these factors (Table I). As shown in Table I, there was a wide range in these values among the patients studied.

Among patients with severe aortic regurgitation (Table 2), there was no significant difference in mean values for left ventricular end-diastolic pressure, peak systolic pressure, or estimated left ventricular wall thickness in patients with angina pectoris as opposed to those without angina;

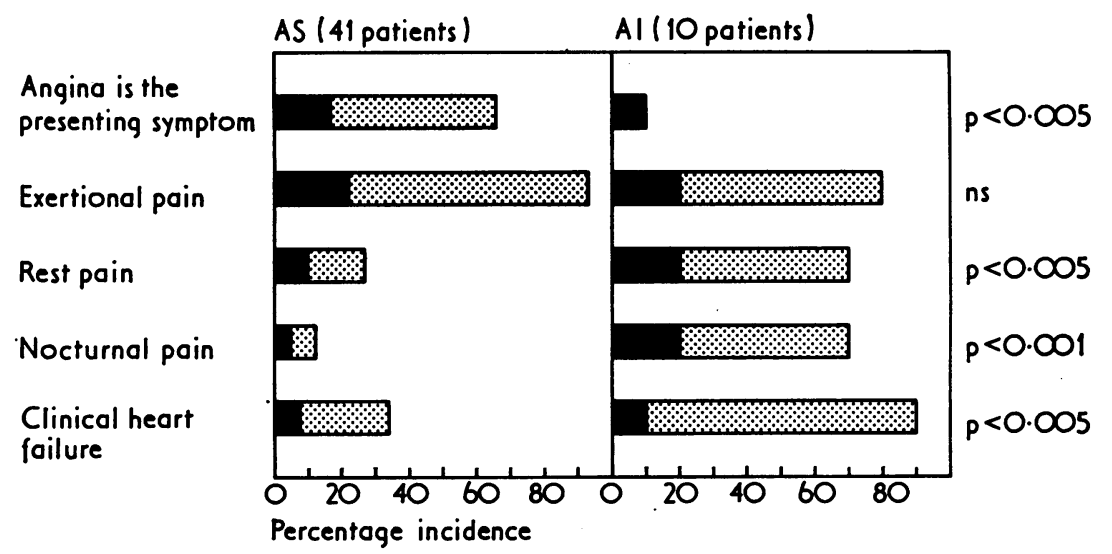

FIG. 2 Clinical characteristics of angina pectoris in patients with aortic stenosis $(A S)$ as opposed to those with aortic regurgitation $(A I)$. The black part of each column represents incidence of coexisting significant coronary artery disease within each category. $P$ value represents statistical significance of the difference in the total incidence of each characteristic between patients with aortic stenosis and those with aortic regurgitation. ns $=$ not significant $(P>0.05)$. Statistical analysis was performed by Fisher's exact probability test. 


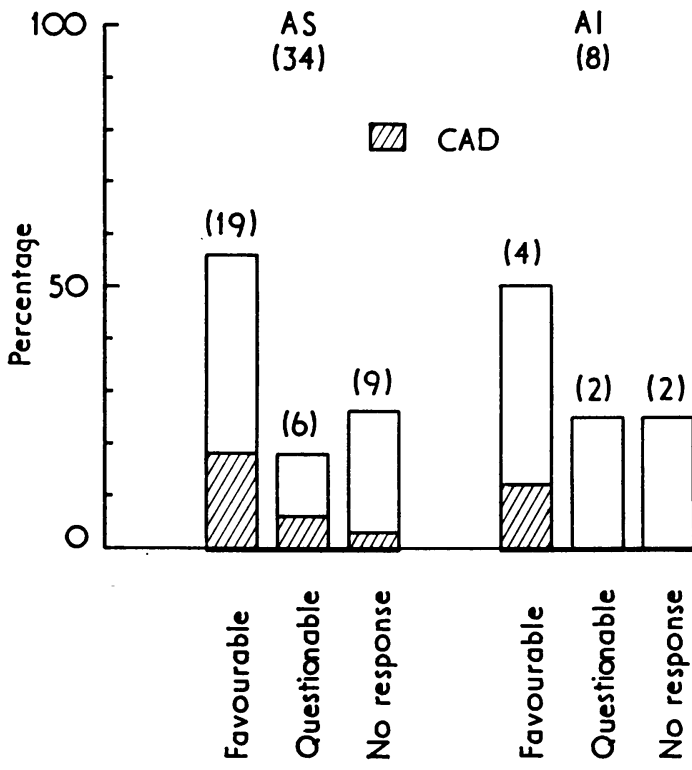

FIG. 3 The response of angina pectoris to nitroglycerin in patients with aortic stenosis (AS) and aortic regurgitation $(A I)$. The number of patients in each category is shown on the top of the corresponding column. The hatched parts of the columns represent patients with significant coronary artery disease $(C A D)$ in each column.

TABLE I Range and mean values of haemodynamic and angiographic findings in patients with aortic stenosis and angina pectoris and findings in patients with aortic stenosis and no angina pectoris

\begin{tabular}{|c|c|c|c|c|c|}
\hline & $\begin{array}{l}\text { Aortic stenosis } \\
\text { with angina } \\
\text { (4I patients) }\end{array}$ & Mean & $\begin{array}{l}\text { Aortic stenosis } \\
\text { without angina } \\
\text { (27 patients) }\end{array}$ & Mean & $P$ value \\
\hline $\begin{array}{l}\text { Cardiac index }\left(1 . \min ^{-m^{-2}}\right) \\
\text { Peak systolic pressure }(\mathrm{mmHg})\end{array}$ & $\begin{array}{l}1.4-4 \cdot 3 \\
148-270\end{array}$ & $\begin{array}{l}(2.6) \\
(202)\end{array}$ & $\begin{array}{l}1.5-3.5 \\
154-234\end{array}$ & $\begin{array}{l}(2.4) \\
(196)\end{array}$ & $\begin{array}{l}\text { NS } \\
\text { NS }\end{array}$ \\
\hline Peak systolic gradient (mmHg) & $\begin{array}{r}19.7-35.9 \\
49-176 \\
6.5-23.4\end{array}$ & $\begin{array}{r}(26.9) \\
(94)\end{array}$ & $\begin{array}{c}20.5-31.1 \\
48-121 \\
6.4-16.1\end{array}$ & $\begin{array}{r}(26.1) \\
(84)\end{array}$ & NS \\
\hline LV end-diastolic pressure ( $\mathrm{mmHg}$ ) & $\begin{array}{l}7-50 \\
0.9-6.6\end{array}$ & $(2.6)$ & $\begin{array}{c}.428 \\
8-58 \\
1.1-7.7\end{array}$ & $\begin{array}{l}(18) \\
(2.4)\end{array}$ & NS \\
\hline $\begin{array}{l}\text { LV end-diastolic volume (ml) } \\
\text { LV ejection fraction } \\
\text { LV wall thickness (mm) }\end{array}$ & $\begin{array}{c}69-506 \\
0.24-0.87 \\
10-22\end{array}$ & $\begin{array}{l}(177) \\
(0.58) \\
(17)\end{array}$ & $\begin{array}{c}60-302 \\
0.33-0.80 \\
11-22\end{array}$ & $\begin{array}{l}(192) \\
(0.57) \\
(16)\end{array}$ & $\begin{array}{l}\text { NS } \\
\text { NS } \\
\text { NS }\end{array}$ \\
\hline
\end{tabular}

$L V=$ left ventricular $P$ value $=$ statistical difference of the difference between values in the two groups; NS = not significant $(>0.05)$.

Statistical analysis was performed by the Student $t$ test.

Pressures in pascal units $(\mathrm{kPa})$ are given in italics.

patients in both subgroups exhibited a wide range in these values. However, patients with angina pectoris tended to have a larger left ventricular end-diastolic volume and lower ejection fraction, but the differences were not quite statistically significant. The cardiac index was significantly lower in the angina group $(\mathrm{P}<0.05)$.

\section{Discussion}

The present study suggests that the absence of a history of angina pectoris in a patient with severe aortic valve disease virtually excludes significan: coronary artery narrowing. This finding is in agreement with that of Bonchek, Anderson, and Rosch (1973), and, therefore, questions the necessity for 
TABLE 2 Range and mean values of haemodynamic and angiographic findings in patients with aortic regurgitation and angina pectoris with findings in patients with aortic regurgitation and no angina pectoris

\begin{tabular}{|c|c|c|c|c|c|}
\hline & $\begin{array}{l}\text { With angina } \\
\text { (Io patients) }\end{array}$ & Mean & $\begin{array}{l}\text { Without angina } \\
\text { (IO patients) }\end{array}$ & Mean & $P$ value \\
\hline $\begin{array}{l}\text { Cardiac index }\left(1 . \mathrm{min}^{-\mathrm{m}^{-2}}\right) \\
\text { Peak systolic pressure }(\mathrm{mmHg})\end{array}$ & $\begin{array}{c}1.5-2.9 \\
109-149 \\
14.5-19.8\end{array}$ & $\begin{array}{l}(2.4) \\
(124) \\
(I 6.5)\end{array}$ & $\begin{array}{c}2.2-4.4 \\
112-172 \\
14.9-22.9\end{array}$ & $\begin{array}{l}(3.3) \\
(139) \\
(18.5)\end{array}$ & $\begin{array}{l}<0.05 \\
\text { NS }\end{array}$ \\
\hline LV end-diastolic pressure ( $\mathrm{mmHg}$ ) & $\begin{array}{c}8-42 \\
I . I-5.6\end{array}$ & & $\begin{array}{l}6-50 \\
0.8-6.7\end{array}$ & $\begin{array}{l}(25) \\
(3.3)\end{array}$ & NS \\
\hline $\begin{array}{l}\text { LV end-diastolic volume (ml) } \\
\text { Regurgitation volume (ml/beat) } \\
\text { LV ejection fraction } \\
\text { LV wall thickness (mm) }\end{array}$ & $\begin{array}{c}178-865 \\
43-167 \\
0.09-0.54 \\
9-20\end{array}$ & $\begin{array}{l}(410) \\
(96) \\
(0.42) \\
(14)\end{array}$ & $\begin{array}{c}204-549 \\
40-284 \\
0.30 .67 \\
9-20\end{array}$ & $\begin{array}{l}(321) \\
(105) \\
(0.54) \\
(15)\end{array}$ & $\begin{array}{l}\text { NS } \\
\text { NS } \\
\text { NS } \\
\text { NS }\end{array}$ \\
\hline
\end{tabular}

$L V=$ left ventricular; $P$ value $=$ statistical significance of the difference between values in the two groups; NS =not significant ( $>0.05$ ).

Statistical analysis was performed by the Student $t$ test.

Pressures in pascal units $(\mathrm{kPa})$ are given in italics.

routine coronary arteriography in adults and older patients with severe aortic valve disease when a history of chest pain cannot be elicited. By following this simple rule, many patients can be spared unnecessary coronary angiography; a procedure that is attended with a finite mortality and morbidity (Adams, Fraser, and Abrams, 1973) as well as inconvenience.

The incidence of significant coronary disease in adults and middle-aged patients with severe aortic valve disease and angina pectoris is probably 20 to 25 per cent. Severe coronary disease was encountered in 12 of 51 such patients in our series and in 5 of 23 similar patients reported by Bonchek et al. (1973). Coronary arteriography is desirable in this group before valve replacement. Severe coronary narrowing may interfere with adequate myocardial perfusion during valve surgery (Flemma et al., 197I). Furthermore, the severity of coronary disease correlates with the operative and postoperative mortality, as well as with the possibility of deterioration or lack of improvement after valve replacement (Roberts and Morrow, 1967; Linhart and Wheat, 1967; Coleman and Soloff, 1970). Aorta-to-coronary saphenous vein bypass is often recommended in conjunction with valve replacement whenever significant coronary artery and valve disease coexist (Flemma et al., 197r).

Angina pectoris is a common feature of symptomatic aortic stenosis in adults; it has been noted in 40 to 70 per cent in different series (Lewes, 1951; Wood, 1958; Baker and Somerville, 1959; Bonchek et al., 1973; Eddleman et al., 1973), and in 60 per cent in the present study. In the present series, when angina pectoris accompanied aortic stenosis, pain was the chief presenting symptom in two-thirds of the cases, which matches an incidence of 56 per cent in the group reported by Baker and Somerville (1959). Furthermore, in our patients with aortic stenosis, angina usually conformed to the classical description; it was mainly effort-related, usually lasted less than 15 minutes, was relieved by rest, and often by nitroglycerin. Nocturnal or rest pain was encountered in a minority of cases ( $17 \%$ ). It is notable that in our cases the clinical pattern of angina pectoris was independent of the coexistence of significant coronary artery disease.

We did not encounter a significant difference at rest in haemodynamic variables, left ventricular wall thickness, or volumes in our group with aortic stenosis and angina pectoris, as opposed to the group without angina pectoris. This suggests that ischaemic pain in severe aortic stenosis may be dependent upon factors other than these gross indices of myocardial oxygen consumption. However, we have not obtained sufficient information concerning certain variables, such as the maximum velocity of pressure development at zero after-load (V-max), which are known to influence oxygen consumption substantially (Braunwald, I97I ; Sonnenblick and Skelton, 197I). In addition, findings at rest do not necessarily reflect haemodynamic response to exercise in a particular patient. On the other hand, it is conceivable that patients with severe aortic stenosis may be limited by other symptoms such as dizziness, syncope, or shortness of breath, which will not allow them to exercise sufficiently to experience angina pectoris.

Angina pectoris with aortic regurgitation has a different pattern from that with aortic stenosis. It is rarely the main presenting symptom and is preceded in the majority of cases by manifestations of 
heart failure $(70 \%$ in the present series). The only patient in our group who presented because of exertional angina pectoris, but did not display features of heart failure, proved to have complete occlusion of the main circumflex branch of the left coronary artery. Episodic chest pain in patients with aortic regurgitation has long been noted to recur at rest, last relatively longer, and to be associated frequently with vasomotor phenomena as well as shortness of breath (Boas, 1922; Schwartz, 1927; Boas, 1935; Friedberg and Sohval, 1939).

The reported incidence of angina pectoris in aortic regurgitation has varied from 3 per cent (Goldschlager et al., 1973) to 50 per cent (Segal, Harvey, and Hufnagel, 1956), depending primarily on the group of patients sudied. The high incidence of rest or nocturnal angina in symptomatic severe aortic regurgitation has been emphasized in the recent reports (Degeorges and Delzant, 1966; Hegglin, Scheu, and Rothlin, I968; Rotman et al., 197I; Spagnuolo et al., 197I). An incidence of 50 per cent of angina in our group reflects the strict criteria that we had adopted for aortic valve replacement; almost all our patients were functional class III or IV, the majority had electrocardiographic evidence of left ventricular hypertrophy and 'strain', and the severity of the disease is further reflected in their haemodynamics and ventricular volumes (Table 2). The higher incidence of angina pectoris in our older patients with severe aortic regurgitation cannot be explained by coexisting coronary artery disease but probably reflects the greater tendency of older patients to have impaired left ventricular performance (Goldschlager et al., 1973). Studies of the natural history of aortic regurgitation have not emphasized the sequence of heart failure followed by angina pectoris. However, examination of recent data indicates parallel curves for heart failure and angina pectoris, with angina occurring in about half the cases (Spagnuolo et al., 1971).

The increased volume load imposed by aortic regurgitation does not seem to be sufficient to cause angina pectoris in the absence of heart failure or significant coronary artery disease. This is probably because of the low 'oxygen cost' of volume load (Braunwald, 197I). With left ventricul'r failure, myocardial oxygen consumption increases because of increased wall tension (Sonnenblick and Skelton, 1971), and impaired myocardial energetics (Gunning and Coleman, 1973), while coronary flow probably decreases because of the decrease in cardiac output and in effective coronary perfusion pressure.

Angina pectoris in aortic regurgitation occurs at rest, improves with mild exercise, and recurs with more vigorous exercise. This interesting clinical observation can be explained by the findings of Levinson, Frank, and Schwartz (1970) that patients with severe aortic regurgitation have a more effective stroke volume and significantly less regurgitation volume in response to moderate exercise. This should lead to a temporary decrease in left ventricular volume, wall tension, and oxygen consumption. More severe exercise, however, increases myocardial oxygen demands through increase in heart rate, along with effects of sympathetic overactivity and enhanced myocardial contractility. Conversely, angina at rest and nocturnal angina, so commonly seen in our patients with severe aortic regurgitation, may be ascribed to the deleterious effects of bradycardia on left ventricular end-diastolic pressure, end-diastolic circumferential stress, and enddiastolic load (Judge et al., 1971).

The favourable response of angina pectoris to nitroglycerin in at least 50 per cent of our patients with aortic valve disease was not dependent upon the coexistence of significant coronary artery disease. In aortic stenosis, nitroglycerin in therapeutic doses decreases left ventricular peak systolic pressure, systolic work, and hence myocardial oxygen consumption (Perloff, Ronan, and deLeon, 1965). In aortic regurgitation, decreased peripheral resistance is expected to lead to an increase in effective stroke work and a significant reduction in regurgitation volume, ventricular diastolic volume, wall tension, and, therefore, oxygen consumption.

We are grateful to Dr. Francois Abboud for valuable suggestions and Mr. Hoang Kaoshing for statistical analysis.

\section{References}

Adams, D. F., Fraser, D. B., and Abrams, H. L. (1973). The complications of coronary arteriography. Circulation, 48, 609.

Baker, C., and Somerville, J. (1959). Clinical features and surgical treatment of fifty patients with severe aortic stenosis. Guy's Hospital Reports, 108, ror.

Boas, E. P. (1922). Diseases of the aorta and aortic valves. Medical Clinics of North America, 6, 615.

Boas, E. P. (1935). Angina pectoris and heart block as symptoms of calcareous aortic stenosis. American fournal of the Medical Sciences, 190, 376.

Bonchek, L. I., Anderson, R. P., and Rosch, J. (1973). Should coronary arteriography be performed routinely before valve replacement? American fournal of Cardiology, 31, 462.

Braunwald, E. (1971). Control of myocardial oxygen consumption. American fournal of Cardiology, 27, 416.

Brockenbrough, E. C., and Braunwald, E. (1960). A new tecnic for left ventricular angiocardiography and transseptal left heart catheterization. American fournal of Cardiology, 6, 1062.

Coleman, E. H., and Soloff, L. A. (1970). Incidence of significant coronary artery disease in rheumatic valvular heart disease. American fournal of Cardiology, 25, 401 . 
Contratto, A. W., and Levine, S. A. (1937). Aortic stenosis with special reference to angina pectoris and syncope. Annals of Internal Medicine, 10, 1636.

Cooper, G., Puga, F. J., Zujko, K. J., Harrison, C. E., and Coleman, H. N. (1973). Normal myocardial function and energetics in volume-overload hypertrophy in the cat. Circulation Research, 32, 140.

Degeorges, M., and Delzant, J. F (1966). Eléments de pronostic de l'insuffisance aortique isolée recuellis chez 206 malades agés de moins de 50 ans. Semaine des Hôpitaux de Paris, 42, II7I.

Dodge, H. T., Hay, R. E., and Sandler, H. (1962). An angiocardiographic method for directly determining left ventricular stroke volume in man. Circulation Research, Ir, 739.

Eddleman, E. E., Frommeyer, W. B., Lyle, D. P., Bancroft, W. H., and Turner, M. E. (1973). Critical analysis of clinical factors in estimating severity of aortic valve disease. American fournal of Cardiology, 3r, 687.

Flemma, R. J., Johnson, W. D., Lepley, D., Jr., Auer, J. E., Tector, A. J., and Blitz, J. (197I). Simultaneous valve replacement and aorta-to-coronary saphenous vein bypass. Annals of Thoracic Surgery, 12, 163.

Friedberg, C. K., and Sohval, A. R. (1939). Nonrheumatic calcific aortic stenosis. American Heart fournal, 17, 452.

Goldschlager, N., Pfeifer, J., Cohn, K., Popper, R., and Selzer, A. (1973). The natural history of aortic regurgitation. American fournal of Medicine, 54, 577.

Greene, D. G., Carlisle, R., Grant, C., and Bunnell, I. L. (1967). Estimation of left ventricular volume by oneplane cineangiography. Circulation, 35, 61.

Gunning, J. F., and Coleman, H. N. (1973). Myocardial oxygen consumption during experimental hypertrophy and congestive heart failure. Fournal of Molecular and Cellular Cardiology, 5, 25.

Hegglin, R., Scheu, H., and Rothlin, M. (1968). Aortic insafficiency. Circulation, 37 and 38, Suppl. 5, 77.

Judge, T. P., Kennedy, J. W., Bennett, L. J., Wills, R. E., Murray, J. A., and Blackmon, J. R. (197I). Quantitative hemodynamic effects of heart rate in aortic regurgitation. Circulation, 44, 355.

Kennedy, J. W., Trenholme, S. E., and Kasser, I. S. (1970). Left ventricular volume and mass from single-plane cineangiocardiogram. A comparison of anteroposterior and right anterior oblique methods. American Heart fournal, 80, 343.

Kumpe, C. W., and Bean, W. B. (1948). Aortic stenosis: a study of the clinical and pathological aspects of 107 proved cases. Medicine, 27, 139.
Levinson, G. E., Frank, M. J., and Schwartz, C. J. (I970). The effect of rest and physical effort on the left ventricular burden in mitral and aortic regurgitation. American Heart fournal, 80, 79r.

Lewes, D. (195I). Diagnosis of aortic stenosis. British Medical Fournal, $1,211$.

Linhart, J. W., and Wheat, M. W. (1967). Myocardial dysfunction following aortic valve replacement. Fournal of Thoracic and Cardiovascular Surgery, 54, 259.

Mackenzie, J. (1925). Diseases of the Heart, 4th ed. Oxford University Press, New York.

McGinn, S., and White, P. D. (1934). Clinical observations on aortic stenosis. American fournal of the Medical Sciences, I88, I.

Perloff, J. G., Ronan, J. A., and deLeon, A. C. (1965). The effect of nitroglycerin on left ventricular wall tension in fixed orifice aortic stenosis. Circulation, 32, 204.

Roberts, W. C., and Morrow, A. G. (1967). Late postoperative pathological findings after cardiac valve replacement. Circulation, 35 and 36, Suppl. I, 48.

Rotman, M., Morris, J. J., Behar, V. S., Peter, R. H., and Kong, Y. (I97I). Aortic valvular disease; comparison of types and their surgical management. American fournal of Medicine, 5I, $24 \mathrm{I}$.

Sandler, H., Dodge, H. T., Hay, R. E., and Rackley, C. E. (1963). Quantitation of valvular insufficiency in man by angiocardiography. American Heart fournal, 65, 501.

Schwartz, S. P. (1927). Paroxysmal cardiac pain. The syndrome in young adults with rheumatic valvular heart disease. American Heart fournal, 2, 497.

Segal, J., Harvey, W. P., and Hufnagel, C. (1956). A clinical study of one hundred cases of severe aortic insufficiency. American fournal of Medicine, 21, 200.

Sonnenblick, E. H., and Skelton, C. L. (197I). Myocardial energetics: basic principles and clinical implications. New England fournal of Medicine, 285, 668.

Spagnuolo, M., Kloth, H., Taranta, A., Doyle, E., and Pasternack, B. (1971). Natural history of rheumatic aortic regurgitation. Criteria predictive of death, congestive heart failure, and angina in young patients. Circulation, 44, 368.

Tuohy, E. L., and Eckman, P. F. (1931). Aortic stenosis with calcareous nodules in the aortic valves. Minnesota Medicine, 14, 289.

Wood, P. (1958). Aortic stenosis. American fournal of Cardiology, 1,553 .

Requests for reprints to Professor Lotfy L. Basta, University of Oklahoma Health Sciences Center, Post Office Box 26901, Oklahoma City, Oklahoma 73190, U.S.A. 